\title{
Quando o amor é o problema: feminismo e poliamor em debate
}

\author{
Antonio Cerdeira Pilão' \\ 0000-0002-3966-5531 \\ 'Universidade Federal Fluminense, Campos, RJ, Brasil.28010-385 - pucg@vm.uff.br
}

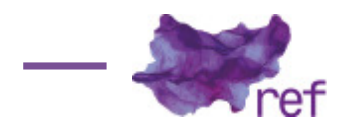

Resumo: Poliamor é um termo que designa a possibilidade de estabelecer múltiplas relações afetivas e sexuais de forma concomitante, consensual e igualitária. No presente artigo é analisado como esse modelo de conjugalidade foi apresentado, interpretado e debatido na internet por feministas e poliamoristas. O objetivo é investigar em que medida ele foi entendido como contraditório ou compatível com o feminismo. A pesquisa foi conduzida a partir da análise de três textos que apresentam problemas na aplicação do poliamor em um contexto de desigualdades de gênero, de raça e de classe social.

Palavras-chove: conjugalidade; sexualidade; feminismo; não monogamia; poliamor

When love is the problem: feminism and polyamory in debate

Abstract: Polyamory is a term that refers to the possibility of establishing multiple affective and sexual bonds in a concomitant, consensual and egalitarian way. This paper analyzes how polyamory was presented, interpreted and debated by feminists and polyamorists on the internet. The goal is to investigate to what extent polyamory was understood as contradictory or compatible with feminism. The research was conducted from the analysis of three texts that present problems in the application of polyamory in a context of gender, racial and class inequalities.

Keywords: Conjugality; Sexuality; Feminism; Non-monogamy; Polyamory.

\section{Introdução}

Muito se tem falado sobre transformações na intimidade, nas relações de gênero e conjugais a partir da década de 1960. A chamada "revolução sexual" ou movimento "contracultural" teria levado a uma maior equidade nas relações entre homens e mulheres, a uma proliferação dos arranjos conjugais e a uma desarticulação entre casamento e experiência sexual e amorosa, ainda que o uso do termo "revolução" tenda a superestimar essas e outras transformações ocorridas no período (Michel BOZON, 1995; 2004).

A institucionalização do divórcio e o surgimento de um "movimento homossexual" (Edward MacRAE, 1985; Regina FACCHINI, 2003) no Brasil, nos anos 1970, contribuíram para o questionamento da norma do casamento indissolúvel e heterossexual. Assim, ao invés da superação da monogamia, o que se observou, no final do século XX, foi a sua expansão para as relações homossexuais e a sua transformação para um modelo "serial", também conhecido como "monogamia em série".

Apesar de a fidelidade ter persistido como um ideal fundamental para a sustentação de um vínculo amoroso (Mirian GOLDENBERG, 2010; Maria Luiza HEILBORN, 2006) entre os casais ditos "igualitários" ou "modernos", são encontrados aqueles que optam por um projeto de "relacionamento aberto" na esfera sexual (Tania SALEM, 1989; HEILBORN, 2004). De forma semelhante, os adeptos de swing mantêm relações sexuais extraconjugais, desde que de forma negociada, consentida e sob a presença de ambos os cônjuges (Olivia VON DER WEID, 2010; Maria SILVÉRIO, 2014). 
Há, no caso dos swinguers, como também entre os casais "igualitários", uma maior abertura no âmbito sexual, sem haver, no entanto, uma abertura amorosa. Assim, embora as pesquisas citadas mostrem um questionamento da fidelidade sexual, do ponto de vista amoroso perpetua-se o imaginário de que dois sujeitos devem se amar exclusivamente, mesmo que não durante toda a vida.

O termo poliamor, criado nos Estados Unidos, nos anos 1990, se refere à possibilidade de se estabelecer múltiplas relações afetivo-sexuais de forma concomitante, consensual e igualitária (Daniel CARDOSO, 2010; Antonio PILÃO; GOLDENBERG, 2012). O poliamor emerge, portanto, como uma alternativa à monogamia que não se restringe à defesa da não exclusividade sexual, afirmando ser não apenas possível, mas preferível amar a mais de uma pessoa e manter mais de um relacionamento ao mesmo tempo (PILÃO, 2013).

Os poliamoristas consideram o poliamor um vínculo mais livre do que a monogamia, uma vez que o estabelecimento de um relacionamento não é impeditivo de outros. A desvantagem da monogamia estaria também na menor honestidade entre os parceiros em função da preferência pela infidelidade em detrimento do questionamento da regra da exclusividade afetivo-sexual. Os poliamoristas acreditam ainda que o poliamor é mais igualitário do que a monogamia, já que não se basearia em uma dupla moral sexual, sendo marcado pelo combate ao machismo e pela equiparação da liberdade afetivo-sexual feminina à masculina (PILÃO; GOLDENBERG, 2012, p. 6869; PILÃO, 2015, p. 396).

No Brasil, o termo poliamor ganhou circulação na virada do milênio. Em 2004, foi criado o grupo "Poliamor Brasil" na extinta rede social Orkut. Nos anos seguintes foram publicadas matérias na mídia (Aziz FILHO, 2006; Joaquim Ferreira dos SANTOS, 2007; Ciça VALLERIO, 2007), organizados encontros entre poliamoristas nas cidades de São Paulo e do Rio de Janeiro e feitas as primeiras referências nas áreas da psicologia (Terezinha FÉRES-CARNEIRO, 2008; Henrique de Carvalho PEREIRA, 2009) e do Direito da família. ' Em 201 1, a Rede Pratique Poliamor Brasil foi criada com o objetivo de unificação e de transformação do poliamor em um movimento social. O momento de maior visibilidade pública se deu em 2012, com a divulgação do reconhecimento em cartório da "primeira união poliafetiva do Brasil" (G1 BAURU E MARÍLIA, 2012). Também foi nesse ano que as primeiras publicações a respeito do tema foram realizadas no âmbito das ciências sociais (Vania SILVA; Geraldo NERES; Rosangela SILVA, 2017, p. 92-99). ${ }^{2}$

Tendo em vista que a emergência do poliamor se dá sob a influência de um ideário igualitário (Meg BARKER; Darren LANGDRIDGE, 2010; Christian KLESSE, 2011; PILÃO, 2015), o objetivo deste trabalho é compreender como o poliamor foi apresentado, interpretado e debatido entre feministas e poliamoristas na internet. Assim, a proposta é investigar em que medida os ideais poliamoristas de liberdade e igualdade foram entendidos como contraditórios ou compatíveis com os do feminismo.

Para tanto, foram analisadas três publicações sobre poliamor que ganharam destaque nos meios feminista e não monogâmico: a primeira, intitulada "Poliamor é para pessoas ricas e bonitas", escrita por Vivienne CHEN (2014) e publicada no blog http://blogueirasfeministas.com/. A segunda, de autoria de Gabriella BEIRA (2014), publicada na revista Capitolina, "Por que o poliamor e as relações livres podem ser privilégios para os homens?". A terceira foi publicada no Facebook com o título "Então toma", em 2015, e republicada no blog da autora, Laura ELISA (2015), com o título "Sobre poliamor".

Em comum entre os três textos há o fato de não serem escritos por membros do movimento poliamorista e terem como principal objetivo apresentar problemas na aplicação do poliamor em um contexto de desigualdade de gênero, racial e econômica. Nesse sentido, a categoria-chave de acusação ao poliamor é a de que se trata de uma forma de "privilégio". Apresento adiante como cada uma dessas críticas é construída e como repercute nos meios feministas e poliamoristas.

\section{"Poliamor é para pessoas ricas e bonitas"}

A crítica produzida no texto não é direcionada à ideologia poliamorista, ou seja, não se trata de uma defesa da monogamia ou do amor romântico. Ao contrário, alguns elementos do texto explicitam críticas à monogamia e até mesmo uma exaltação do poliamor como uma forma mais admirável de relacionamento. Dentre os mais notáveis, a afirmação de que a monogamia e o capitalismo são dois sistemas de exploração interconectados que devem ser enfrentados.

A autora compara o poliamor a uma alimentação saudável, afirmando que ambas são formas de "privilégio", de modo que o problema não está nessas práticas, mas na falta de

\footnotetext{
' As primeiras considerações sobre o poliamor no Direito foram feitas pelo juiz e professor da UFBA Pablo Stolze GAGLIANO (2008) em STOLZE, Pablo. "Direitos da(o) amante. Na teoria e na prática (dos tribunais)". Revista Jus Navigandi, Teresina, ano 13, n. 1841, 16 jul. 2008. Disponível em

https://jus.com.br/artigos/1 1500. Acesso em 19/05/2019. Disponível em http://jus.com.br/artigos/1 1500/direitos-da-oamante. Último acesso em 26/08/2017.

2 Nesta parte do trabalho os autores analisam o desenvolvimento de produções acadêmicas sobre poliamor em Portugal e no Brasil.
} 
democratização delas. O objetivo, portanto, não é limitar o poliamor, abandoná-lo ou defender uma moral monogâmica, mas expandi-lo, fazendo com que não seja uma possibilidade apenas para pessoas "ricas", "bonitas" e com o "tempo livre".

Embora publicado por feministas, a crítica se concentra, em especial, nos efeitos da desigualdade social, que faria com que a escolha pela monogamia fosse mais segura e viável entre os mais pobres. Dentre as razões apontadas, as dificuldades financeiras para o controle de natalidade e para a prevenção e tratamento de doenças sexualmente transmissíveis, a maior vulnerabilidade à agressão física e moral e a menor disponibilidade de tempo livre.

Ao elencar inúmeras razões para as dificuldades de praticar o poliamor entre pessoas pobres, a autora questiona a atitude de poliamoristas de autopromoção e de condenação de monogâmicos. Isso porque ela acredita que os poliamoristas perdem de vista a influência das estruturas sociais nas escolhas individuais, quando não reconhecem que a liberdade possível para eles não o é para todos. Assim, ao invés de buscarem ampliar a prática do poliamor por meio do enfrentamento das desigualdades sociais, os poliamoristas estariam vangloriando-se de seu privilégio - afirmando-se "especiais", "intelectualmente esclarecidos" e "sexualmente libertos". Portanto, deslegitimariam a escolha pela monogamia, condenando aqueles que não teriam as mesmas oportunidades que eles para se tornarem poliamoristas.

Não é incomum encontrar referências na literatura sobre poliamor e sua pretensa superioridade em relação à monogamia. Uma das primeiras e mais conhecidas militantes poliamoristas procurou demonstrar a superioridade ética do poliamor, afirmando que ele contribui para tornar as pessoas mais evoluídas, criando ambientes familiares mais saudáveis, atenciosos, amorosos e seguros para as crianças (Deborah ANAPOL, 2010, p. 147-153). A busca poliamorista de ajudar os "sexualmente marginalizados" foi reconhecida como uma "fantasia narcisista", na qual, ao invés de criticar as estruturas de poder, individualizaria e psicologizaria os processos sociais (Jin HARITAWORN; Chin-ju LIN; Christian KLESSE, 2006, p. 519-523).

Chama atenção o fato de as blogueiras feministas terem traduzido e publicado o texto, mas em debate numa lista de e-mails mostrarem discordâncias. Na publicação, elas já haviam afirmado que o processo de tradução foi resultado de uma intensa discussão, de modo a não haver consenso em torno de seus argumentos. Muitas delas se mostraram reticentes quanto à publicação de um texto crítico ao poliamor, compreendendo a luta feminista como necessariamente antimonogâmica:

É às mulheres que a monogamia é imposta (ou alguém tem alguma ilusão que existe ou existiu monogamia para os homens? Ou, se preferirem outro termo, a fidelidade). A monogamia escraviza e automatiza a sexualidade feminina. Se isso não é motivo pra usarmos nomenclaturas claras e definirmos qual a nossa estratégia de combate à monogamia, não sei o que é.

Outra colocação recorrente entre as blogueiras feministas foi a de que é pretensioso tratar o poliamor como uma realidade restrita a pessoas ricas, por esse pensamento presumir a falta de agência dos pobres e a incapacidade destes de enfrentarem a monogamia. Nesse sentido, uma delas afirma que: "gente pobre é gente: existe mas também pensa e sente; achar que só gente rykka e phynna pratica poliamor ou enxerga as relações dessa maneira é bem elitista".

Nos grupos virtuais de poliamoristas o texto foi recebido com menos críticas que na lista de e-mails das blogueiras feministas, afirmando-se que os mais ricos levam vantagem sobre os mais pobres, dispondo de maior tempo livre e condição financeira para manter mais de um relacionamento consensual. Nesse sentido, um homem argumenta que:

Sim, o Poliamor é pra pessoas ricas e bonitas, não só porque a dinâmica desses relacionamentos se torna quase impossível pra quem é pobre, mas tb porque quem é rico e bonito escapa frequentemente do julgo das pessoas simplesmente porque dispõem de mais privacidade ou mais prestígio. É uma pena, não deveria ser assim, mas é o que ocorre com mais frequência.

Tal leitura sobre a influência da "situação de classe" na prática do poliamor é recorrente no meio não monogâmico brasileiro. Embora haja uma variedade de perspectivas ideológicas entre os praticantes, a socialista é bem significativa, motivo pelo qual não é incomum se deparar com discursos em que se afirma a impossibilidade de o poliamor se tornar majoritário em uma sociedade desigual como a brasileira. Nessa leitura, o poliamor só seria pleno em uma estrutura social de tipo comunista onde - sem barreiras econômicas - todos seriam livres para definirem com quantos parceiros querem se relacionar.

A relativa aceitação da referida crítica não deve gerar a ilusão de que os poliamoristas brasileiros são efetivamente ricos. O que observei ao longo da pesquisa de mestrado e de doutorado é que estes são oriundos, sobretudo, das classes médias urbanas e não de uma classe dominante, de grandes proprietários e empresários. Tratam-se, predominantemente, de jovens, em torno de 20 e 30 anos, com uma situação financeira precária e uma vida profissional instável. Muitos dependem da ajuda financeira de familiares para sua subsistência e a de seus filhos, alguns dividem apartamento com amigos ou parceiros, outros vivem com os pais. Ainda assim, o recorte de classe 
é relevante para a compreensão do grupo, já que, em sua maioria, não emana das camadas sociais mais pobres, concentrando-se, sobretudo, nas maiores e mais ricas cidades do país, morando em bairros de classe média e tendo acesso à educação de nível superior.

Embora o texto tenha fomentado debates em grupos não monogâmicos a respeito da inadequação do poliamor a pessoas oriundas de estratos sociais mais baixos, também favoreceu discussões a respeito do caráter excludente de certos perfis estéticos. Em um desses debates, um poliamorista mostrou a dificuldade que enfrenta para desconstruir o seu padrão de beleza, de modo a tentar não excluir pessoas gordas do seu campo de desejos:

Algo que comecei a refletir a poucos dias [sic] é também como é difícil, se não impossível, desconstruir isso em mim mesmo. Uma coisa é tratar racionalmente certos padrões e agir contra eles, mas como eu faço isso com meu tesão? Confesso, que apesar do afeto, eu realmente não sinto tesão por pessoas gordas. Não me entendam mal, é algo que me pergunto constantemente e tento procurar uma resposta. É fato que nossa cultura emprega essa norma e nós todos somos impregnados por ela, mas fica a questão, como desconstruir o tesão??? Fomos estragados por criação, será que dá para reverter isso quando se trata do tesão? Será que até que acabemos com a norma o tesão à [sic] pessoas gordas ele sempre cairá no campo do fetiche?

A discussão mostra existir uma ruptura entre um projeto político-ideológico de combate à hierarquização dos corpos que objetiva torná-los, sem exceção, amáveis e desejáveis, e um desejo concreto, excludente e seletivo, visto como resultado de anos de inculcação de uma sociedade "machista", "gordofóbica", "racista" e "transfóbica".

O paradoxo descrito está na conjugação de um discurso poliamorista que enfatiza a libertação do desejo e a espontaneidade dos afetos, em casos onde isso representa o rompimento com o compromisso ético igualitário de lutar contra "opressões". Nesse caso, a precedência do igualitarismo caminha no sentido de uma defesa, ainda que dolorosa, da repressão/transformação dos desejos que são vistos como hierarquizantes e opressores. Uma mulher sugere alguns caminhos para o autor da mensagem promover essa transformação das hierarquias estéticas/corporais em prol de desejos tidos como mais inclusivos:

Acho que a sinceridade dele comprova a maestria do texto postado. Conseguimos perceber como as relações funcionam, e a questão do colega seria justamente como desconstruir internamente a ponto de reverter essa condição [...] Somos induzidos a pensar que gosto é gosto, mas já sabemos que não é bem assim que a banda toca [...] Eu não sei se ajuda, mas sempre que eu quero ter tesão em alguma pessoa, eu imagino eu dando pra ela, seja homem ou mulher, imagino a cara da pessoa gozando, imagino o ápice do sexo, línguas, dedos, anal [...] Quando percebo já estou cheia de tesão na pessoa. Hahahaha faço isso com diversas pessoas na rua, eu exercito o erótico da minha mente [...] fazer isso sempre me ajuda a sentir tesão em todos os tipos de corpos!

A sugestão de "exercitar" a atração sexual por todos os corpos mostra a problematização da espontaneidade do desejo e a precedência da posição ideológica igualitária. Outra participante do fórum questiona essa atitude, afirmando que a desconstrução deve ser geracional e não interna e individual porque vai implicar que as pessoas se relacionem umas com as outras sem efetivamente desejarem, apenas se esforçando para tal: "Acho que o esforço grande tem que ser na desconstrução visando às gerações futuras, pq eu não vou querer me relacionar com alguém que está comigo para ser 'correto', ou 'moderno'".

A discussão se desenrola em torno dessa tensão entre desconstruir em si um desejo que se reconhece estar baseado em padrões estéticos excludentes ou deixá-lo fluir de forma mais "espontânea", não intervindo sobre ele de maneira vista como artificial. Nesse tópico de discussões caminhou-se mais no sentido da necessidade de um trabalho sobre si, buscando os meios mais eficientes para ampliar o espectro de pessoas desejáveis, percebendo diferentes tipos de beleza, valorizando detalhes e dimensões não visuais das interações, por exemplo.

No Brasil, de acordo com Mirian Goldenberg (2006), o corpo trabalhado, cuidado, sem marcas indesejáveis (rugas, estrias, celulites, manchas) e sem excessos (gordura, flacidez) constituise como um aspecto central da atração sexual. Assim, ele deve ser moldado, manipulado, trabalhado, costurado, enfeitado, escolhido, construído, produzido e imitado, não se tratando de um corpo indistinto, genérico (p. 1 18-121). Segundo a antropóloga, a cultura da beleza e aparência física no país se relaciona com o grande número de brasileiras que realizaram cirurgias plásticas, especialmente as de lipoaspiração, colocando o Brasil na segunda posição mundial em número de procedimentos, atrás apenas dos Estados Unidos.

A problematização da hierarquização dos corpos, divididos em belos e indesejáveis, jovens e velhos, válidos e inválidos, tem se intensificado no movimento feminista, particularmente, na póspornografia, no transfeminismo e no ativismo gordo. Esses movimentos voltados às corporalidades dissidentes questionam o desejo como uma realidade individual, espontânea e incontrolável, para tratá-lo como aprendido, como uma construção social passível de ser transgredida: 
Nos toca entonces comenzar la difícil y urgente tarea de replantearnos el deseo. Será entonces necesario dejar de lado el yo deseo, para entrar en un crear deseo, en construirlo colectivamente, reconociéndonos y teniendo siempre bien claro que no deseamos libre ni autónomamente. Está en nuestras manos el generar nuevas representaciones, construir nuevos imaginarios, dar lugar a otros cuerpos. Necesitamos un cuestionamiento transfeminista del deseo, que atraviese, transgreda, transforme (Lucrecia MASSON, 2013, p. 234).

Esses movimentos buscam o enfrentamento de padrões corporais e das fronteiras que estabelecem o que é um corpo "normal", procurando valorizar as "carnes" que sobram, que faltam, as que estão velhas, as doentes e as não funcionais (MASSON, 2013, p. 226). A busca pela descolonização e desnormatização dos corpos se dá a partir da afirmação do corpo como uma ficção políitica, de corpos como entidades criativas, que não querem se adaptar, se "torturar" com dietas e exercícios físicos. Assim, os proletários da beleza e da saúde, como se refere o "Manifesto Gordx: o punk nunca fará dieta" (Constanza A. CASTILLO; Samuel HIDALGO, 2014), defendem a necessidade de que os desejos sejam desaprendidos, tornando esses corpos desejantes também desejáveis.

Maria Eduarda RAMOS (2015) afirma ser um desafio para a pornografia feminista representar corpos não hegemônicos fora das categorizações fetichistas da pornografia convencional. Segundo a autora, o pós-pornô é uma ferramenta política feminista que visa à invenção de corpos e desejos, desconstruindo padrões estéticos sem estabelecer um modelo fixo alternativo, exibindo artistas com corpos gordos, velhos, trans, com próteses, além de práticas sexuais não genitais ( $p$. 160-163).

A crítica divulgada pelas blogueiras feministas ao caráter excludente do poliamor, pautado na desigualdade social e/ou estética, gera entre os poliamoristas, além de defesas, reflexões sobre de que forma o poliamor pode estar sub-repticiamente reforçando hierarquias e padrões tidos como excludentes e opressores. Num plano mais subjetivo, tenta-se, alinhado ao referido discurso feminista, desconstruir desejos; já no econômico, acredita-se ser necessário enfrentar o capitalismo para que as relações não monogâmicas não sejam uma forma de privilégio de classe.

É possível observar entre os poliamoristas que a valorização do autocontrole das emoções se expressa até mesmo no desejo sexual (ou na falta dele) que pode ser visto como problemático, operando como um poderoso mecanismo de hierarquização que exclui e oprime corpos que fogem a determinados padrões estéticos. Assim, se a liberdade é fundamental na legitimação do poliamor, servindo como principal alicerce de oposição à monogamia, ela deve necessariamente caminhar, lado a lado, numa tensa harmonia, com o compromisso e o escrutínio ético desenvolvido com base na valorização da igualdade.

\section{"Por que o poliamor e as relações livres podem ser privilégios para os homens?"}

O segundo texto analisado é brasileiro e por essa razão faz referência não apenas ao poliamor, mas também às relações livres, ${ }^{3}$ utilizando os termos indistintamente. ${ }^{4} \mathrm{O}$ "privilégio" associado ao poliamor e à RLi não é de classe social ou de beleza, como no anterior, mas de gênero. Embora crítico, também não defende a moral monogâmica ou condena a ideologia poliamorista, afirmando apenas o risco de essa teoria ser apropriada pelo "patriarcado", de modo que as mulheres seriam vistas como objetos sexuais sempre disponíveis. Nessa apropriação, as mulheres que dizem "não" seriam rotuladas como "moralistas", "caretas" e "possessivas", perdendo a capacidade de legitimarem a recusa à investida sexual masculina.

Há uma ambiguidade na descrição do poliamor, que também é visto como potencialmente libertador e empoderador da sexualidade feminina. A superação de uma condição de submissão feminina a partir de relações não monogâmicas é vista como possível quando a prática não emana de uma demanda masculina por sexo "fácil", mas como uma escolha feminina, formulada apenas por e para elas.

Em grupos e páginas feministas no Facebook a divulgação da matéria gerou grande repercussão, contando com centenas de compartilhamentos e milhares de comentários. Variadas foram as interpretações, divergências e hostilidades geradas a partir das discussões. Em algumas delas, foram questionadas as intervenções masculinas, afirmando-se que o texto foi escrito por uma mulher e que a pauta é feminina.

\footnotetext{
3 "A Rede Relações Livres (Rede RLi) tem como objetivo livrar-se do tabu da monogamia (norma moral de exclusividade sexual e afetiva) através da conformação de relações livres: relações que respeitem a liberdade afetiva e sexual das pessoas, priorizando a autonomia e emancipação dos indivíduos." Disponível em http://relacoeslivres.com.br/. Último acesso em 20/02/2017.

${ }^{4}$ Ao longo do período de realização da pesquisa (201 1-2017) houve um acelerado crescimento das relações livres, que perderam o caráter de um grupo local, restrito ao Rio Grande do Sul. Com isso, muitas pessoas passaram a participar indiscriminadamente de atividades ligadas a ambos os grupos e a não considerarem relevante construírem distinções, se definindo apenas como "não monogâmicas".
} 
Foi perceptível uma sensação de contentamento com a visibilidade de uma crítica ao poliamor, de modo que muitas mulheres indicaram a leitura a outras amigas, mostrando que haviam conversado com elas sobre o assunto. Mesmo que no texto a crítica não tenha se dado por meio da valorização da monogamia, foi possível encontrar mensagens que utilizaram a matéria com esse fim: "Meu cu... não divido homem com ninguém".

Inúmeras mulheres mostraram se sentir pressionadas por um discurso feminista que vangloria a liberdade e vê a restrição a um único parceiro como uma condição inferior. $O$ uso desses argumentos por poliamoristas parece que tinha o poder de fazê-las sentirem-se mulheres atrasadas, inadequadas, machistas que aceitaram se submeter ao domínio patriarcal da monogamia. Essa defesa da liberdade sexual, que até então estava sendo legitimada por um discurso feminista que atuava sobre elas de maneira coercitiva, sugeria que, para serem verdadeiramente feministas, só sendo poliamoristas. Um elemento que acredito ter intensificado a euforia e a sensação de alívio entre mulheres foi o fato da crítica publicada na revista "Capitolina" ter sido escrita por uma feminista e ser destinada a elas, como se a partir do texto pudessem se libertar da intensa pressão moral poliamorista de serem livres.

Com o texto, essas mulheres conseguiram legitimar uma resposta igualmente feminista contra o poliamor, recusando-o sem que se tornassem um tipo inferior de mulher, atrasado, objeto de posse masculina. Uma delas afirmou que o texto teve o potencial de acolher as mulheres monogâmicas como se dissesse: "olha, não tem nada errado com você, te entendemos".

Por outro lado, a mesma mulher afirmou que essa libertação do julgamento poliamorista é perigosa porque algumas estariam se apoiando no texto para se manterem reprimidas sexualmente, evitando gerar uma transformação em seus comportamentos e sentimentos:

O que eu tô observando e achando complicado é que algumas mulheres tão meio que se agarrando a este texto e desconsiderando que existe aí a necessidade de se desconstruírem, exatamente para que se fortaleçam, que se tem coisa doendo aí qdo se fala em relacionamento aberto vai ser bom tentarmos entender como isso se dá e lógico, respeitando o tempo e as necessidades de cada uma, a condição emocional etc [sic].

Essa mensagem mostra a complexidade do debate, não se tratando apenas de uma defesa contra o ideal não monogâmico de liberdade, considerado desse ponto de vista como opressivo. O poliamor e as relações livres também são considerados empoderadores. Dessa forma, questiona-se a afirmação de que eles seriam privilégios masculinos, por isso implicar uma desconsideração do poder de agência feminino e uma percepção das mulheres como incapazes de se beneficiarem de sua própria liberdade sexual. O mesmo argumento é utilizado para deslegitimar a bissexualidade feminina, como se a liberdade sexual e amorosa de mulheres bissexuais apenas existisse visando ao atendimento dos interesses do patriarcado. Contrariadas, elas reagiriam com sarcasmo contra a representação de que se guiariam para atender às fantasias sexuais masculinas a fim de preservarem os seus relacionamentos (Ani RITCHIE; Meg BARKER, 2007).

Essa leitura de que a liberdade sexual das mulheres serve apenas aos homens é extremamente recorrente nos grupos feministas na internet e, em alguns casos, leva à afirmação de que o poliamor só é desejável após uma revolução que acabe com a opressão de gênero. Enquanto isso não ocorre, a monogamia é preferível, já que o poliamor só serviria como um instrumento de ampliação da dominação e do privilégio masculino. Algumas afirmam que seria ainda melhor não se relacionar com homens, já que, no contexto atual, esta é uma relação inevitavelmente opressiva: "Homens sempre estragam as coisas bonitas". "A ideia [poliamor] é ótima, mas na atual conjuntura, sendo pragmática, tudo que diz respeito a relacionamento quando há um homem envolvido, se torna problemático".

Mas como a publicação na "Capitolina" repercutiu nos grupos não monogâmicos? Parte dos homens discordou do texto e afirmou que é a monogamia que está associada ao machismo e que a não monogamia visa, sobretudo, ao empoderamento das mulheres e à retirada do privilégio histórico da liberdade sexual masculina. Referindo-se a Friedrich Engels, um poliamorista afirma que a monogamia é um instrumento de dominação dos homens sobre as mulheres. Outros homens poliamoristas aceitaram parte da crítica, considerando o machismo um dos resquícios monogâmicos no poliamor.

É interessante destacar a diferença de gênero nas reações ao texto. Enquanto os homens foram mais críticos, as mulheres o receberam com maior entusiasmo, afirmando se tratar de uma discussão ignorada pelos homens, mas fundamental para o empoderamento feminino. As mulheres não consideraram o texto uma crítica ao poliamor, mas uma denúncia contra homens que o utilizam como um "braço do patriarcado". Há, nesse sentido, uma contraposição entre um ideal poliamorista puro e perfeito - igualitário do ponto de vista de gênero - e a prática poliamorista, mais ou menos impura, opressora e machista.

Em geral, quando se discute a opressão de gênero no meio não monogâmico, a visão dos homens é considerada de menor relevância. Suas falas são comumente vistas como tentativas de "silenciamento", discursos que emanam de um opressor que não reconhece o seu privilégio. 
Consideráveis são os efeitos dessa dinâmica, uma vez que a solidariedade feminista parece se sobrepor à poliamorista/RLi, dificultando a construção dessas identidades. Antes de serem poliamoristas essas mulheres são feministas, companheiras de opressão e de luta e, assim, parecem se solidarizar mais com a autora de "Capitolina" do que com os homens poliamoristas e RLis.

Esse conflito identitário contribuiu para o fim do grupo Relações Livres em Porto Alegre (Rio Grande do Sul), em 2015. De um lado, as mulheres da organização identificavam machismo e acobertamento de assédios masculinos por parte de uma das principais lideranças do grupo. De outro, via-se uma radicalidade feminista excessiva e até mesmo uma opressão contra homens, colocando em discussão o tema da "misandria", que inevitavelmente foi recebido com grande revolta por algumas feministas.

A precedência da identidade feminista sobre a não monogâmica favorece uma tensão nas relações entre os gêneros, onde os homens são considerados os "hospedeiros" do "parasita" machismo, deixando de ser companheiros de luta para serem inimigos da luta feminista. Nesse caso, o homem branco, heterossexual e cis ${ }^{5}$ é visto como o principal perigo, o maior adversário; até que se prove o contrário, um intruso e opressor infiltrado no grupo. Tal posição de privilégio e opressão leva à questão de como é possível que mulheres feministas construam uma identidade e organizem uma luta política tendo a seu lado homens brancos e cis. Esse impasse se amplia ao considerarem se relacionar sexualmente com esses homens, parecendo que "dormiriam com os inimigos".

A posição masculina de "inimigo a priori" faz com que seja necessário um esforço por parte dos homens para romper com a condição generalizada de opressores, individualizando-se, diferenciando-se, a fim de se tornarem amáveis e respeitáveis. Para tanto, defende-se nos grupos não monogâmicos uma atitude investigativa e de desconfiança permanente, de modo a enfrentar a tendência denunciada na revista "Capitolina" de que o poliamor seria apropriado pelo patriarcado favorecendo apenas ou, sobretudo, a liberdade sexual masculina.

Alguns homens adotaram um discurso de defesa desse protagonismo feminino, se (des)culpando, mandando os outros homens se calarem e respeitarem o sofrimento delas. Também foi possível observar uma busca no sentido de auxiliarem no processo de identificação de machistas "infiltrados" nos grupos, de modo a operarem um processo de diferenciação, em que, ao reconhecerem e nomearem os machistas, afastariam o risco de serem eles próprios alvos dessas acusações. Nada é mais desmoralizante para um homem poliamorista do que ser rotulado de machista e abusivo; todo o ideal de eu, valorizado, ético, superior, desmorona com essas poderosas e perigosas palavras.

Gostaria de ressaltar uma contradição na posição sobre a monogamia das referidas mulheres feministas. De um lado, pretendem a libertação da sexualidade feminina, afirmando o seu desejo e equiparando-o ao masculino. Nessa leitura, o homem não é visto como ameaça, mas potencial parceiro e sua sexualidade livre, um ideal a ser perseguido.

Na segunda leitura, os homens são considerados opressores e a expansão das práticas (hetero)sexuais femininas não é vista positivamente, uma vez que é interpretada como opressão, como assujeitamento ao interesse masculino e objetificação da mulher. A sexualidade é interpretada, nesse caso, como masculina em si e por isso é negativa. A recusa (hetero)sexual é vista como instrumento de empoderamento, de modo que o limite trazido pelo "não" ganha contornos de um importante mecanismo de enfrentamento da opressão masculina. Enquanto na primeira leitura o "sim" é interpretado como libertador e empoderador, equiparando a liberdade sexual feminina à masculina, na segunda, é visto como submissão.

Tais tensões no movimento feminista, nos anos 1980, foram abordadas por Gayle RUBIN (1984), por exemplo, ao se referir aos debates relativos à pornografia e ao sadomasoquismo. As visões oscilavam entre a recusa, por se tratar de formas de objetificação da mulher e o reconhecimento como legítimas, em função de estarem assentadas num princípio de consensualidade. A autora afirma que o grupo mais conservador, que adotava discursos "antisexo" (p. 301-309), considerava a liberdade sexual uma extensão do privilégio masculino.

Analisando esse debate, Maria Filomena GREGORI (2003) argumenta que as feministas radicais conceberam a pornografia, o sadomasoquismo, a prostituição e a promiscuidade sexual como instituições heterossexuais que levavam as mulheres a uma condição necessária de submissão, violência e perigo. Na contramão dos discursos "anti-sexo", teriam proliferado vozes feministas defendendo tais práticas, questionando o mapa generalista e totalizante da subordinação patriarcal, a demonização da sexualidade e a teoria da objetificação do corpo feminino (p. 100-107).

Carole VANCE (1984), importante referência sobre o tema, também critica a ideia de que mulheres, em uma cultura patriarcal, seriam incapazes de consentirem sobre a prática sexual. A autora defende a necessidade de reconhecer as formas como as mulheres foram humilhadas por meio do sexo sem, no entanto, afirmar que o sexo é em si humilhante (p. 1-7). Rubin (1984) identifica essa visão como uma "demonologia" que ressalta o que há de pior na sexualidade, para rejeitála como um todo. A liberação sexual deveria atender tanto a homens quanto a mulheres, de modo

\footnotetext{
${ }^{5}$ A categoria cisgênero, ou apenas cis, se refere às pessoas que se identificam com o gênero que lhes foi atribuído
} no nascimento, ou seja, aquelas que não são transgênero. 
a possibilitar uma visão positiva do sexo e o rompimento da compreensão da sexualidade como inteiramente opressora (p. 301-303). Assim, o feminismo não poderia operar apenas baseado no medo e em busca do distanciamento do perigo e da opressão masculina, mas também na direção do prazer e da satisfação sexual (VANCE, 1984, p. 23-24).

Com base nessas questões é perceptível que há uma tensão no pensamento feminista que também atravessa o meio não monogâmico. Em que medida a luta se concentra contra a liberdade sexual masculina ("opressora") ou em favor de sua expansão às mulheres, consideradas excluídas de algo visto positivamente e afirmado como privilégio? A negativização da liberdade sexual masculina torna mais difícil a consideração das relações não monogâmicas como uma forma de empoderamento feminino. O poder feminino nessa perspectiva é antipoliamor porque se afirma na recusa.

\section{Feminismo negro}

O terceiro texto mantém o sentido de exclusão envolvido na prática do poliamor, dessa vez concentrando a referência à situação de mulheres negras, gordas, trans e com deficiência. Diferentemente dos demais, não foi originalmente escrito em um blog, mas no Facebook e utiliza mais a primeira pessoa do singular: "Eu desafio sinceramente vocês a me convencer que essa história de poliamor me contempla".

Novamente a crítica não se de desenvolve a partir da exaltação de qualidades da monogamia, mas do caráter excludente do poliamor que é considerado uma "bolha", habitada por pessoas brancas, magras, com acesso à informação e economicamente afluentes. A mensagem é destinada a esse grupo privilegiado de poliamoristas que pode desconstruir a monogamia e que, por essa razão, "desfila" arrogância, buscando convencer mulheres de que o poliamor é o ideal.

A autora defende que mulheres negras, gordas, trans e com deficiência não se inserem nesse debate porque ou não têm o direito nem à monogamia, sendo excluídas do mercado matrimonial, ou estão presas a relacionamentos abusivos nos quais são economicamente dependentes de seus maridos. A discussão sobre poliamor nesse grupo de mulheres é vista como insignificante, já que quem não é "amável" não poderia pleitear viver inúmeros amores.

Embora inicialmente não se enfatize a questão de gênero na construção da "bolha poliamorista", na sequência do texto a autora argumenta não existir nada de revolucionário em um homem ser não monogâmico, já que se trataria de um privilégio masculino histórico. A diferença recente estaria na construção de um novo discurso de legitimação da dominação masculina, uma narrativa politicamente "engajada" e libertária. Nela, o desconforto feminino com a liberdade masculina seria visto como decorrente de seus ciúmes e de sua falta de autocontrole. Todo o sofrimento causado pela exclusão e solidão dessas mulheres seria reduzido a uma responsabilidade delas próprias, consideradas "exageradas" e "paranoicas".

A busca por torná-las não monogâmicas é vista como uma grande afronta, uma desconsideração do lugar que ocupam e da opressão que sofrem. Assim, a autora afirma que, para ir além da monogamia, é necessário antes ser digna da monogamia, posição possível apenas para as brancas, magras e sem deficiências. Nessa perspectiva, o ideal poliamoroso só pode ser aspirado pelo feminismo branco, uma vez que a conjugalidade da mulher negra é considerada historicamente "abusiva" e "escondida".

A ideia de que as mulheres negras são um objeto sexual sempre disponível também é abordada no blog "Blogueiras Negras" como um dos principais desafios para se pensar positivamente as relações não monogâmicas. Isso porque ser não monogâmica e negra parece reforçar o estigma de corpo que serve, que não recusa, como se elas não pudessem ser donas de sua própria sexualidade, de suas escolhas e de seu prazer. Nesse sentido, a não monogamia não é entendida como uma libertação ou uma ruptura, mas como subserviência e manutenção de uma tradição que as reservou o papel de "concubinas", "rameiras", "amantes" e "empregadas assanhadas":

Somos mães solteiras. Mulheres que jamais tiveram a oportunidade de ambientar o imaginário daqueles que concebem histórias de amor, que seguem os padrões monogâmicos. Nas novelas, o caminho que leva uma personagem negra ao altar é sempre tortuoso. Um envolvimento inapropriado, uma diferença de classe gritante, a luta contra o preconceito e a realidade de uma família não tradicional. Não se admite que mulheres negras tenham o direito à tranquilidade de uma vida monogâmica. Fomos forjadas tais quais mantas kevlar ${ }^{6}$ para suportar, unilateralmente, as nuances de uma vida de batalha. Fomos ensinadas a ser sozinhas. A parceria de um relacionamento conjugal monogâmico não se encaixa com a nossa melanina (Mariana BARBOSA, 2014).

\footnotetext{
- O dicionário de Cambridge define kevlar como um material resistente, que suporta altas temperaturas e cuja produção é utilizada na fabricação de chapéus e coletes à prova de bala. A associação das mulheres negras às mantas kevlar tornou-se conhecida a partir de um trecho da música "Mulheres Negras", de Yzalú Feat Eduardo (2012), em que é afirmado que: "Mulheres negras são como mantas Kevlar, preparadas pela vida para suportar; o racismo, os tiros, o eurocentrismo abalam, mas não deixam nossos neurônios cativos". Publicado em 22/08/2012. Disponível em https://www.youtube.com/watch?v=2DV5N1prJhl. Último acesso em 20/12/2016.
} 
A proposta das blogueiras negras é questionar a universalização de um discurso em que se afirma o poliamor como uma demanda intrinsecamente feminista. Nessa perspectiva, a representação da monogamia como uma prisão só poderia ser formulada pelas mulheres brancas, a quem ela é destinada. Assim, é afirmado existirem particularidades nos processos de exclusão, de violência e de objetificação da mulher negra que colocam as seguintes questões: Por que a monogamia nunca foi uma opção para elas? Por que não são amáveis? Por que os homens negros mantêm relações públicas com brancas e escondidas com negras? Por que esses homens paridos e educados por mulheres negras reproduzem um comportamento negligente e violento?

As questões colocadas pelas blogueiras negras remetem às formulações a respeito da interseccionalidade, considerando que a discriminação da mulher negra não pode ser reduzida ao somatório do racismo e do sexismo. Assim, ainda que sob alguns pontos essas mulheres partilhem de experiências similares às das mulheres brancas e às dos homens negros, experimentam discriminações particulares à condição de "mulheres negras" (Kimberlé CRENSHAW, 1989).

Referindo a uma tendência histórica do sistema jurídico norte-americano, a autora aponta para a desconsideração de crimes de estupro cometidos por homens brancos contra mulheres negras. Parte da argumentação jurídica estaria na afirmação de que a única mulher passível de ter a dignidade e a moralidade rompida é a branca. A mulher negra, em contrapartida, seria representada como naturalmente licenciosa e sempre pronta para o intercurso sexual (CRENSHAW, 1989, p. 157-160).

As blogueiras negras, inspiradas nas formulações de Crenshaw, defendem uma visão interseccional (Patricia ANUNCIADA, 2015) onde a opressão de gênero é compreendida necessariamente em articulação à raça e à classe social. Assim, defendem a necessidade de "enegrecer o feminismo" (Larissa SANTIAGO, 2013), considerando os anseios e perspectivas das mulheres negras e questionando o fato de suas demandas estarem situadas à margem das agendas de um movimento que privilegia as mulheres brancas de classe média.

Se o feminismo ("branco") problematiza o discurso de homens não monogâmicos, interessados apenas em aumentar o número de parceiras, o feminismo negro levanta novos problemas renegados pelas brancas, como a hiperssexualização e a objetificação histórica do corpo das negras. Ambos os feminismos convergem para o rompimento de uma perspectiva mais generalizada no meio poliamorista que afirma a monogamia como uma instituição repressora, hipócrita e machista e que apresenta o poliamor como a sua solução ideal.

O discurso do feminismo negro gerou grande repercussão nos grupos não monogâmicos. De um lado, procurou-se compreender as razões da crítica, voltando a atenção à questão do racismo nas escolhas amorosas e argumentando que a liberdade em uma estrutura social desigual é apenas privilégio. De outro, foram perceptíveis reações de discordância e de afirmação de que a crítica teria sido motivada por "ódio". Em um desses comentários, uma mulher branca questiona a autora afirmando que o poliamor não é excludente:

Que pessoinha mais cheia de ódio... sinceramente, eu estou fora dos padrões (gorda, baixinha e com cabelo cacheado) e não sou excluída de nada disso... sou casada há 4 anos, e nesse tempo já tive vários relacionamentos poliamorosos. Nunca me senti com baixa estima no meio de qualquer grupo que seja, e não tô ligando nem um pouco pro que os outros tão pensando de mim [...] Falta é amor no coração dessa mulher...

Em outra crítica, o texto é referido como um "ataque" às mulheres não monogâmicas, desvirtuando o problema dos verdadeiros inimigos: os homens e o machismo. Questiona-se, assim, a colocação da mulher branca e não monogâmica como privilegiada e exaltada socialmente por ter vários companheiros. Nesse sentido, são compartilhadas experiências de intenso sofrimento dessas mulheres em função da incompatibilidade com a monogamia, o que busca reforçar a sua posição de vítima da opressão e não de opressora ou de privilegiada:

Eu passei a vida inteira sendo rejeitada e não assumida por não ser monogâmica por essência [...]. Isso para não falar na humilhação pública que eu conheci tantas vezes por ser uma "vagabunda", já tive coisas atiradas em mim quando andava na rua, já fui cuspida literalmente, apontada, já tive meu nome em porta de banheiro... Fui humilhada quando estava grávida de todos os jeitos possíveis, ouvindo "hoje é um filho, amanhã é uma aids", já fui estuprada ouvindo "cala a boca, vc é uma puta, trepa comigo e com todo mundo", já fui estuprada, me culpei por isso e não denunciei porque, afinal, "eu namoro e tô traindo, então mereço". Eu só encontrei paz para quem eu sou dentro da não monogamia, eu só encontrei algum homem que me assumisse quando eu vim pra cá, e mesmo assim foi difícil e é difícil até hoje [...] até hoje eu caio nessa merda de machismo recorrentemente de gente que tem vergonha de dizer que me pegou, ou sente que está fazendo alguma coisa meio errada porque eu sou mãe, porque eu tenho um companheiro, porque eu estou grávida, porque. Jura que aí vem um texto me dizer que na verdade não monogamia é papo de garotas brancas magras padrão para serem vangloriadas por mais menininhos? Ah, faça-me o favor. [...] 
Em grupos não monogâmicos as críticas mais contundentes ao texto vieram de mulheres brancas que compõem a grande maioria nesse meio. Talvez a pouca participação de mulheres negras tenha contribuído para que os discursos que demonstraram maior solidariedade à autora do texto viessem predominantemente de homens brancos que não foram os alvos centrais das críticas. Um deles diz concordar com o texto, afirmando que para ser efetivamente "revolucionário" não basta desconstruir a monogamia, sendo necessário atentar às diferentes formas de opressão que se manifestam também nos relacionamentos poliamorosos:

Vejo na experiência de amigas negras, trans, gordas ou portadoras de deficiência que elas se veem deixadas de lado em grupos e ambientes não monogâmicos, seja no poliamor, na RLi ou em outra forma de não-monogamia. Elas são sempre os relacionamentos secundários, muitas vezes casuais e puramente sexuais, mesmo em espaços que dizem ser contra hierarquização de relacionamentos.

É interessante destacar que na publicação da revista "Capitolina" as mulheres não monogâmicas tenderam a apoiar a autora da crítica e os homens foram mais resistentes, procurando se mostrar diferenciados, portanto, como não machistas. Há uma inversão nessa relação, de modo que os homens assumiram uma posição compreensiva e de defesa do texto das feministas negras, enquanto algumas mulheres se sentiram agredidas, afirmando se tratar de um discurso de ódio, injusto e vitimário.

A imensa maioria de mulheres brancas nos grupos não monogâmicos favoreceu essa tensão, já que parte da crítica atingia sua posição social. O texto promoveu um rompimento com a condição de duplamente oprimidas das mulheres (brancas) não monogâmicas, que ao mesmo tempo, têm que enfrentar o fardo de serem mulheres em uma sociedade machista e serem não monogâmicas em uma sociedade monogâmica.

Ao sofrerem críticas, viram sua identidade de oprimidas ameaçada. Para agravar o incômodo, não só saíram do papel de oprimidas como foram vistas como privilegiadas e parte responsável pela verdadeira opressão, aquela praticada contra a mulher negra. Em matéria escrita por uma integrante do "Blogueiras Negras", publicada na Folha de S. Paulo por João Paulo CUENCA (2015), a autora lamenta a falta de empatia de feministas brancas com a exclusão e a inferiorização das mulheres negras.

Adriana PISCITELLI (2008) afirma - em torno das tensões internas ao movimento feminista que algumas correntes consideraram que valorizar essas diferenças debilitava um pressuposto político relevante de identidade entre mulheres. O feminismo radical da segunda onda se caracterizaria por minimizar diferenças que não fossem as sexuais, conferindo-lhes absoluta primazia. Assim, as discriminações vinculadas à classe e raça não encontrariam espaço nessas formulações (p. 265-266).

Shulamith FIRESTONE (1976) teria considerado o racismo uma realidade específica da cultura ocidental, enquanto a luta das feministas deveria ir além dessa cultura particular, remetendo à centralidade concedida à diferença sexual em termos universais. De forma semelhante, Rubin (1975) não desenvolveria uma análise interseccional, mas analógica, desconsiderando a articulação entre raça e gênero, voltando-se apenas à construção de comparações e paralelismos entre diferentes formas de opressão (PISCITELLI, 2008, p. 265).

Acredito que a resistência de parte das poliamoristas brancas à crítica de feministas negras se dá pela recusa de um feminismo interseccional que questiona a universalização das categorias "mulher" e "patriarcado". Isso porque o movimento político dessas mulheres brancas caminha no sentido de mostrarem como são os homens os verdadeiros inimigos e de afirmarem que todas as mulheres são vítimas de uma estrutura social machista. Ao serem elas também criticadas, responsabilizadas pela opressão ou vistas como privilegiadas, há uma espécie de "curto-circuito" que favorece uma forte reação de resistência. Enquanto nos grupos não monogâmicos os homens afirmam mais constantemente o seu próprio privilégio e a condição de gênero opressor, o reconhecimento de privilégios por parte das mulheres brancas, habituadas a se construírem subjetivamente como oprimidas, parece um grande desafio.

\section{Considerações finais}

A valorização das conquistas feministas e a concepção de que homens e mulheres têm os mesmos direitos nos relacionamentos amorosos é uma tônica dos discursos de poliamoristas. Há, portanto, uma crença no meio poliamoroso de que o "machismo" é incoerente com o poliamor, ainda que nos grupos pesquisados seja perceptível um processo permanente de acusação/ identificação de "machistas", "assediando" mulheres em busca de sexo fácil.

Outra realidade mencionada por vezes em tom de lamento é a busca de homens por uma mulher que possa ser acrescida à sua relação diádica heterossexual. Nesse caso, as namoradas ou esposas são vistas como influenciadas a atenderem aos desejos de seus parceiros. Esses dois cenários recorrentes de acusação mostram uma problematização do desejo sexual não 
monogâmico masculino, considerado potencialmente machista, perigoso e condenável, em contraposição ao feminino, que seria legítimo quando não submetido ao do parceiro.

O "machismo" funciona nas redes poliamoristas como uma categoria de acusação. Ninguém se afirma "machista", mas há um permanente patrulhamento dos comportamentos e dos discursos. Assim, numa abordagem mais radical, até que se prove o contrário, todos os homens são considerados machistas e potencialmente "abusivos". Outra posição - difundida principalmente entre os homens - recusa a divisão generalizante e abstrata das mulheres como "oprimidas" e os homens como "opressores". Afirma-se que o machismo gera prejuízo para ambos e que existem muitos homens que, como eles, são "diferenciados". Por vezes, as mulheres que consideram todos os homens "inimigos" são acusadas de feministas "radicais", "sectárias", "feminazistas" ou "femistas".

Embora nas redes poliamoristas a busca por igualdade de gênero se manifeste de diferentes formas, gerando conflitos e tensões, a superação do machismo e da opressão feminina é vista como condição necessária ao poliamor. Assim, para as feministas poliamoristas, lutar contra o patriarcado é necessariamente enfrentar a "repressão monogâmica" da mulher. Para tanto, citam alguns clássicos como Emma Goldman, Friedrich Engels, Alexandra Kollontai e Simone de Beauvoir. Portanto, ainda que se manifestem múltiplos feminismos, é inegável que não há poliamor fora de um ideário igualitário.

Apesar do discurso poliamorista ter pretensões universalistas, propondo a superação da norma monogâmica, os três textos analisados neste artigo apresentam posições críticas ao poliamor, voltadas a um pretenso caráter elitista e privilegiado. É importante abordar a ambiguidade dessas afirmações, já que a ideia de privilégio implica a posse de características vistas socialmente como positivas, mas que não são universalmente distribuídas.

Há, nesse sentido, a compreensão de que as desigualdades sociais levam a liberdade poliamorista a ser inviável para a maior parte das pessoas. Ademais, a defesa da generalização dessa liberdade é vista como problemática porque ela ignoraria a real situação dos corpos, dispostos em hierarquias que os dividiriam em dominantes e dominados. O poliamor seria, portanto, um discurso utópico, ingênuo e abstrato, que diria respeito, sobretudo, à situação do homem branco, escolarizado e com boa posição econômica, não sendo possível para todas as pessoas aspirarem à liberdade não monogâmica, dentre elas: mulheres negras, pobres, gordas e deficientes.

Os poliamoristas são vistos nas referidas críticas feministas como ocupando posições de prestígio na hierarquia social e como tendo dificuldade em reconhecer o seu próprio privilégio, a sua condição inalcançável para a maior parte das pessoas. Para agravar o descontentamento, ainda responsabilizariam os oprimidos por viverem sob a égide da monogamia, desconsiderando que as desigualdades sociais impedem a universalização da liberdade sexual e amorosa. Essa crítica é estendida às mulheres brancas que mostrariam pouca empatia com a situação das negras, adotando um feminismo universalista que as veria como unificadas por uma mesma opressão, aquela praticada por homens.

Enquanto os poliamoristas veriam o amor positivamente, como uma conexão espontânea e genuína de indivíduos livres, nas críticas apresentadas, a liberdade é um privilégio. Assim, ao invés de considerar que boa parte dos males da sexualidade se resolveria a partir da superação da monogamia e da defesa de mais amor e afeto entre as pessoas, nas referidas críticas o amor não é visto como solução, mas como parte do problema, por ser seletivo e excludente, atendendo a normas e hierarquias.

\section{Referências}

ANAPOL, Deborah. Polyamory in the $21^{\text {st }}$ Century: Love and Intimacy with Multiple Partners. Maryland: Rowman \& Littlefield, 2010.

ANUNCIADA, Patricia. "Feminismo interseccional: um conceito em construção". Blogueiras negras, 29/09/2015. Disponível em http://blogueirasnegras.org/2015/09/29/feminismo-interseccional-umconceito-em-construcao/. Último acesso em 29/08/2017.

BARBOSA, Mariana. “\#Monogamiapraquem?”. Blogueiras negras, 04/09/2014. Disponível em http:/ /blogueirasnegras.org/2014/09/04/monogamia-pra-quem/.

BARKER, Meg; LANGDRIDGE, Darren. "Whatever happened to non-monogamies? Critical reflections on recent research and theory". Sexualities, v. 13, n. 6, p. 748-772, 2010.

BEIRA, Gabriella. "Por que o poliamor e as relações livres podem ser privilégios para os homens?". Capitolina, 15/1 1/2014. Disponível em http://www.revistacapitolina.com.br/por-que-o-poliamor-erelacoes-livres-podem-ser-privilegios-para-os-homens/.

BOZON, Michel. "Amor, sexualidade e relações sociais de sexo na França contemporânea". Revista Estudos Feministas, v. 3, n. 1, p. 122-135, 1995. 
BOZON, Michel. Sociologia da sexualidade. Rio de Janeiro: EDUFGV, 2004.

CARDOSO, Daniel. Amando vári@s - Individualização, redes, ética e poliamor. 2010. Dissertação (Mestrado) - Universidade Nova de Lisboa, Lisboa.

CASTILLO, Constanza A.; HIDALGO, Samuel. "Manifesto Godx: o punk nunca fará dieta". Revista Rosa, 04/02/2014. Disponível em https://medium.com/revista-rosa-1/manifesto-gordx-4873f9e3ccf6. Acesso em 12/1 1/2017.

CHEN, Vivienne. "Poliamor é para pessoas ricas e bonitas". Blogueiras Feministas, 19/02/2014. Tradução de Gui Beno. Disponível em https://blogueirasfeministas.com/2014/02/19/poliamor-e-parapessoas-ricas-e-bonitas/.

CRENSHAW, Kimberlé. Demarginalizing the Intersection of Race and Sex: A Black Feminist Critique of Antidiscrimination Doctrine, Feminist Theory and Antiracist Politics. Chicago: University of Chicago Legal Forum, 1989. p. 139-167.

CUENCA, João Paulo. "Stephanie Ribeiro: feminismo branco não liga para negras". Folha de $S$. Paulo, 2015. Disponível em http://wwwl.folha.uol.com.br/colunas/joaopaulocuenca/2015/11/ 170581 3-stephanie-ribeiro-eu-ainda-nao-sou-mulher-agoraequesaoelas.shtml\#_=_. Último acesso em 13/10/2018.

ELISA, Laura. "Sobre poliamor". Marginália, 03/06/2015. Disponível em https://negrasolidao.wordpress. com/2015/06/03/sobre-poliamor/.

FACCHINI, Regina. "Movimento homossexual no Brasil: recompondo um histórico". Cadernos Arquivo Edgard Leuenroth, Unicamp, v. 10, n. 18/19, p. 79-123, 2003.

FÉRES-CARNEIRO, Terezinha. "Pesquisa e prática clínica: construindo articulações teóricas". Psicologia: Reflexão e Crítica, Porto Alegre, v. 21, n. 3, p. 349-355, 2008.

FILHO, Aziz. "Amor demais". Revista Isto É, 18/10/2006. Disponível em https://istoe.com.br/4456_AMOR +DEMAIS/.

FIRESTONE, Shulamith. A dialética do sexo. Rio de Janeiro: Labor, 1976.

G1 BAURU E MARÍLIA. União estável entre três pessoas é oficializada em cartório de Tupã, SP, 23/08/ 2012. Disponível em http://gl .globo.com/sp/bauru-marilia/noticia/2012/08/uniao-estavel-entre-trespessoas-e-oficializada-em-cartorio-de-tupa-sp.html.

GOLDENBERG, Mirian. "O corpo como capital: para compreender a cultura brasileira". Arquivos em movimento, v. 2, n. 2, p. 115-123, 2006.

GOLDENBERG, Mirian. Por que homens e mulheres traem? Rio de Janeiro: Best bolso, 2010.

GREGORI, Maria Filomena. "Relações de violência e erotismo". Cadernos Pagu, n. 20, p. 87-120, 2003. Disponível em http://ref.scielo.org/q3rt4n. Acesso em 14/10/2017. ISSN 0104-8333. http:// dx.doi.org/10.1590/S0104-83332003000100003.

HARITAWORN, Jin; LIN, Chin-ju; KLESSE, Christian. "Poly/logue: A Critical Introduction to Polyamory". Sexualities, v. 9, n. 5, p. 515-529, 2006.

HEILBORN, Maria Luiza. Dois é par: gênero e identidade sexual em contexto igualitário. Rio de Janeiro: Garamond, 2004.

HEILBORN, Maria Luiza. "Entre as tramas da sexualidade brasileira". Revista Estudos Feministas, v. 14, n. 1, p. 43-59, jan./abr. 2006.

KLESSE, Christian. "Notions of Love in Polyamory - Elements in a Discourse on Multiple Loving". Laboratorium, v. 3, n. 2, p. 4-25, 2011.

MacRAE, Edward. O militante homossexual no Brasil da abertura. 1985. Tese (Doutorado em Antropologia) - Faculdade de Filosofia, Letras e Ciências Humanas, Universidade de São Paulo, São Paulo.

MASSON, Lucrecia. "Un rugido de rumiantes, apuntes sobre la disidencia corporal desde el activismo gordo". In: SOLÁ, Miriam; URKO, Elena. Transfeminismos - epistemes, fricciones y flujos. Navarra: Txalaparta, 2013. p. 225-233. 
PEREIRA, Henrique de Carvalho. "Da metamorfose dos deuses: capitalismo e arquétipo no século XXI". Estudos e Pesquisas em Psicologia, v. 9, n. 2, p. 376-388, 2009.

PILÃO, Antonio Cerdeira; GOLDENBERG, Mirian. "Poliamor e monogamia: construindo diferenças e hierarquias". Revista Ártemis, v. 13, p. 61-73, jan./jul. 2012.

PILÃO, Antonio Cerdeira. "Reflexões sócio-antropológicas sobre Poliamor e amor romântico". Revista Brasileira de Sociologia da Emoção, v. 12, n. 35, p. 505-524, 2013.

PILÃO, Antonio Cerdeira. "Entre a liberdade e a igualdade: princípios e impasses da ideologia poliamorista". Cadernos Pagu, n. 44, p. 391-422, jun. 2015. ISSN 1809-4449. Disponível em https:/ /periodicos.sbu.unicamp.br/ojs/index.php/cadpagu/article/view/8637379. Acesso em 14/10/2017.

PISCITELLI, Adriana. "Interseccionalidades, categorias de articulação e experiências de migrantes brasileiras". Revista Sociedade e Cultura, v. 11, n. 2, p. 263-274, 2008.

RAMOS, Maria Eduarda. Pornografia, resistências e feminismos: estratégias políticas feministas de produções audiovisuais pornográficas. 2015. Tese (Doutorado em Ciências Humanas) Universidade Federal de Santa Catarina, Florianópolis.

RITCHIE, Ani; BARKER, Meg. "Hot bi babes and feminist families: Polyamorous women speak out". Lesbian and Gay Psychology Review, v. 8, n. 2, p. 141-151, 2007.

RUBIN, Gayle. “The traffic in Women: Notes on the 'Political Economy of Sex'”. In: REITER, Rayna. Toward an Anthropology of Women. New York: Monthly Review Press, 1975. p. 157-210.

RUBIN, Gayle. "Thinking sex: notes for a radical theory of politics of sexuality". In: VANCE, Carol (Org.). Pleasure and danger: exploring female sexuality. Nova York: Routledge, 1984. p. 267-293.

SALEM, Tania. "O casal igualitário: princípios e impasses". Revista Brasileira de Ciências Sociais, v. 3, n. 9, p. 24-37, fev. 1989.

SANTIAGO, Larissa. "Enegrecer o feminismo, uma questão de prática". Blogueiras negras, 09/07/ 2013. Disponível em http://blogueirasnegras.org/2013/07/09/enegrecer-o-feminismo-uma-questaode-pratica/. Último acesso em 29/08/2017.

SANTOS, Joaquim Ferreira dos. O futuro é do poliamor. "Matutina - Segundo Caderno", O Globo, 15/ 06/2007, p. 3.

SILVA, Vania Sandeleia Vaz da; NERES, Geraldo Magella; SILVA, Rosangela da. "Michel Foucault e o Poliamor: cuidado de si, parresía e estética da existência". Revista Tempo da Ciência, v. 24, n. 48, 2017. Disponível em http://e-revista.unioeste.br/index.php/tempodaciencia/article/view/18968. ISSN 1414-3089. Acesso em 14/12/2017.

SILVÉRIO, Maria. Swing: Eu, tu ... eles. Lisboa: Chiado, 2014.

VALLERIO, Ciça. "Uma forma diferente de amar". Jornal Estadão, 25/08/2007. Disponível em https:/ /emais.estadao.com.br/noticias/geral,uma-maneira-diferente-de-amar, 40947.

VANCE, Carole (Ed.). Pleasure and Danger: Exploring Female Sexuality. New York: Routledge, 1984.

VON DER WEID, Olivia. "O adultério consentido". Revista Estudos Feministas, v. 18, n. 3, p. 789-810, 2010.

Antonio Cerdeira Pilão (tonipilao@gmail.com) é Professor Associado de Ciências Sociais (UFF-Campos), doutor em Antropologia Cultural (PPGSA-UFRJ) e mestre em Sociologia e Antropologia pelo mesmo Programa. Coordenador do grupo de pesquisa "Sexualidades e Conjugalidades (não)monogâmicas" (NESEG-UFRJ) e autor dos artigos: "Entre a liberdade e a igualdade: princípios e impasses da ideologia poliamorista", "Poliamor e monogamia: construindo diferenças e hierarquias", entre outros. 


\section{COMO CITAR ESSE ARTIGO DE ACORDO COM AS NORMAS DA REVISTA}

PILÃO, Antonio Cerdeira. "Quando o amor é o problema: feminismo e poliamor em debate". Revista Estudos Feministas, Florianópolis, v. 27, n. 3, e55097, 2019.

\section{CONTRIBUIÇÃO DE AUTORIA}

Não se aplica. Colaboraram com o autor as alunas Angelica Gomes da Silva e Tenesse Kelly Moraes de Lima, que fazem parte do grupo de pesquisa "Sexualidades e conjugalidades (não) monogâmicas".

\section{FINANCIAMENTO}

O presente trabalho foi realizado com apoio parcial da Coordenação de Aperfeiçoamento de Pessoal de Nível Superior - Brasil (PDSE-CAPES) - Código de Financiamento 001.

\section{CONSENTIMENTO DE USO DE IMAGEM}

Não se aplica

\section{APROVAÇÃO DE COMITÊ DE ÉTICA EM PESQUISA}

Não se aplica

\section{CONFLITO DE INTERESSES}

Não se aplica

\section{LICENÇA DE USO}

Este artigo está licenciado sob a Licença Creative Commons CC-BY International. Com essa licença você pode compartilhar, adaptar, criar para qualquer fim, desde que atribua a autoria da obra.

\section{HISTÓRICO}

Recebido em 02/02/2018

Reapresentado em 15/10/2018

Aprovado em $01 / 11 / 2018$

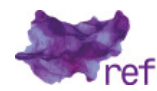

